\title{
A INDISSOCIABILIDADE ENTRE A EXTENSÃO, O ENSINO E A PESQUISA: O TRIPÉ DA UNIVERSIDADE
}

\author{
THE INDISSOCIABILITY \\ BETWEEN EXTENSION, \\ EDUCATION AND RESEARCH: \\ THE UNIVERSITY TRIPOD
}

\author{
Fabiola Hermes Chesani* \\ Luana Bertamoni Wachholz** \\ Márcia Aparecida Miranda de Oliveira*** \\ Caroline da Silva**** \\ Maria Eduarda Luz $z^{* * * * *}$ \\ Francielly Alexandre Fabris******* \\ Bruna Engel ${ }^{* * * * * * * *}$
}

\section{RESUMO}

O objetivo deste artigo é apresentar como foi estimulado o processo de um projeto de extensão que preconiza a indissociabilidade entre o ensino, a pesquisa e a extensão. A metodologia do projeto de extensão apoia-se na concepção Freireana de educação, sendo que as atividades de extensão são compostas por encontros com os cuidadores de crianças internadas num hospital pediátrico e no ambulatório de endocrinologia. As atividades desenvolvidas com o ensino aconteceram com o Círculo de Cultura com os cuidadores, nas atividades de formação continuada entre docentes e discentes e com a disciplina de Fisiopatologia de órgãos e sistemas. As atividades de pesquisa envolveram a aplicação de um questionário sobre qualidade de vida de crianças e apresentações de trabalhos em eventos. A indissociabilidade pesquisa, extensão e ensino convoca os docentes e os discentes universitários à articulação de saberes, o saber da experiência, o saber do conhecimento e o saber pedagógico, além de beneficiar diretamente a comunidade envolvida.

Palavras-chave: extensão comunitária; educação em saúde; comunicação interdisciplinar.

\footnotetext{
*Professora da Universidade do Vale do Itajaí (UNIVALI), SC - Brasil. E-mail: fhcfisio@hotmail.com

**Professora da Universidade do Vale do Itajaí (UNIVALI), SC - Brasil. E-mail: luana_@univali.br

***Professora da Universidade do Vale do Itajaí (UNIVALI), SC - Brasil. E-mail: marciaoliveira3@terra.com.br

****Aluna de Graduação da Universidade do Vale do Itajaí (UNIVALI), SC - Brasil. E-mail: caroline.silva3006@gmail.com

*****Aluna de Graduação da Universidade do Vale do Itajaí (UNIVALI), SC - Brasil. E-mail: caroline.silva3006@gmail.com

******Aluna de Graduação da Universidade do Vale do Itajaí (UNIVALI), SC - Brasil. E-mail: mariaeduardaluzz@gmail.com

*******Aluna de Graduação da Universidade do Vale do Itajaí (UNIVALI), SC - Brasil. E-mail: brunaengel@edu.univalli.br
} 


\section{ABSTRACT}

This article aims to report the process of developing an outreach project that advocates the inseparability between teaching, research and outreach. The methodology was based on the Freirean concept of education. The outreach activities were carried out through meetings with the caregivers of children hospitalized in a pediatric hospital and in an outpatient clinic of endocrinology. The activities which involved teaching where developed with the Círculo de Cultura and caregivers as well as in teachers and students continuous training and in the discipline Pathophysiology of Organs and Systems. The research activities involved questionnaires on children's quality of life and presentation of papers in events. The indissociability between teaching, research and outreach calls for university teachers and university students to articulate knowledge - the knowledge of experience, the knowledge of content and the knowledge of pedagogy, to bring benefits to the community.

Keywords: outreach for community; health education; interdisciplinary communication.

\section{Introduçáo}

O tripé formado pelo ensino, pela pesquisa e pela extensão forma o eixo fundamental da Universidade brasileira e não pode ser compartimentado. O artigo 207 da Constituição Brasileira de 1988 dispóe que "as universidades [...] obedecerão ao princípio da indissociabilidade entre ensino, pesquisa e extensão" (BRASIL, 1998).

A indissociabilidade é um princípio orientador da qualidade da produçáo universitária, porque afirma como necessária a tridimensionalidade do fazer universitário autônomo, competente e ético.

As relaçóes dipé, como a articulação entre o ensino e a extensão, o ensino e a pesquisa e muito menos frequente a pesquisa e a extensão, fortalecem algumas dimensões educacionais e enfraquecem outras. A relação entre o ensino e a extensáo direciona para uma formação preocupada com os problemas da sociedade em que se vive, mas esquece da disseminaçáo da produçáo do conhecimento científico produzido por esta dualidade. A forte e tradicional relação entre o ensino e a pesquisa reforça o conhecimento científico empírico e tecnológico e desconsidera as reais necessidades sociais, éticas e políticas da sociedade. Já a relação entre a pesquisa e a extensão minimiza o ensino, o que acarreta a perda do sentido da universidade, isto é, a dimensão formativa (MOITA; ANDRADE, 2009).

Atualmente, o discurso que se constrói sobre Extensão Universitária quer apontar para a superação da forte dicotomia até entáo existente entre a Pesquisa e o Ensino. A Extensão Universitária articularia o Ensino e a Pesquisa de forma indissociável e, portanto, viabilizaria a relaçáo transformadora entre Universidade e Sociedade (GARRAFA, 1987/1988).

A fim de minimizar o reducionismo que se vivencia nas práticas universitárias, considerando a produção do novo saber com metodologias inovadores, ou ainda a intervenção nos processos sociais, este artigo objetiva apresentar como foi estimulado o processo de um projeto de extensão que preconiza a indissociabilidade entre o ensino, a pesquisa e a extensão.

\section{Método}

As ações aconteceram no projeto de extensão "Educação e humanização em saúde junto aos cuidadores de crianças e adolescentes internados no HUPA e usuários do Ambulatório de Endocrinologia na Unidade de Saúde Familiar e Comunitária (USFC)", a partir de estratégias interativas no período de fevereiro a dezembro de 2016. 
Este projeto tem o objetivo geral de promover educaçáo e humanizaçáo em saúde junto ao público-alvo, visando a troca de saberes e experiências entre os participantes da comunidade, por meio de rodas de conversa e outras estratégias interativas. E especificamente de realizar educação em saúde no ambiente hospitalar (Hospital Universitário Pequeno Anjo/HUPA) e no Ambulatório de Endocrinologia Pediátrica na USFC da Universidade do Vale do Itajaí - UNIVALI, bem como auxiliar no desenvolvimento de competências e habilidades, necessários aos profissionais da saúde, como liderança e tomada de decisão, visando a formação de acadêmicos mais humanistas, com olhar interdisciplinar; mobilizar os cuidadores a participarem ativamente dos encontros semanais, a partir do acolhimento; contribuir para a consolidaçáo dos projetos pedagógicos dos cursos envolvidos; incentivar a produção científica; relacionar os dados do projeto com as disciplinas ministradas em sala de aula, como conteúdos da ética profissional, políticas públicas, e, também, incluindo a promoção, educação e humanização em saúde.

O projeto é constituído por uma equipe interdisciplinar de 3 docentes e 22 discentes dos cursos de Fisioterapia, Psicologia e Nutrição. As reuniōes entre discentes e docentes aconteceram na Universidade e os encontros com os cuidadores e pacientes aconteceram no ambiente hospitalar (HUPA) e no Ambulatório de Endocrinologia Pediátrica na USFC da UNIVALI.

A metodologia das atividades do projeto apoia-se na concepçáo Freireana de educação, mais especificamente o Círculo de Cultura, o qual busca a participação do sujeito, o diálogo e a escuta humanizada (FREIRE, 1987). Para Gadotti (1991), o Círculo de Cultura é uma unidade de ensino que substitui a escola tradicional, formado por um grupo de pessoas para discutir seu trabalho, as quais têm uma situação existencial em comum, mas não por meio da concepção bancária, mas sim pela tese de que existem dois que sabem coisas distintas e que podem aprender mutuamente.

$\mathrm{O}$ método consiste em momentos que se inter-relacionam: a investigaçáo temática, a tematização e a problematização. A etapa da investigação é a busca de tema ou a palavra geradora, que é aquela extraída do universo do cotidiano das pessoas. A etapa da tematização é o momento de tomada de consciência do mundo, através da análise dos significados sociais dos temas geradores. A etapa da problematização é a etapa em que ocorre a superação da visão mágica e acrítica do mundo, para uma postura conscientizada (FREIRE, 1987; GADOTTI, 1991). Todas as etapas aconteceram no mesmo encontro com os cuidadores, pois se acontecesse uma etapa por encontro, os cuidadores não seriam as mesmas pessoas, o que descaracterizaria um Círculo de Cultura.

As atividades do projeto foram baseadas nas seguintes etapas: convite aos cuidadores para participarem de um grupo de discussóes, no qual emergem os temas geradores; divulgaçáo das açóes e atividades do projeto através de boletim informativo e colaboradores do HUPA e do Ambulatório; realização de encontros diários, com duração aproximada de 45 a 60 minutos, com a participação de bolsistas acadêmicos provenientes dos estágios e também acadêmicos voluntários; utilização de jogos, recursos pedagógicos, situaçóes-problemas e dinâmicas de grupo que favoreçam a reflexão e a troca de saberes sobre principais agravos à saúde da criança, que mobilizem o saber e a busca de soluçôes para a autonomia e auto-sustentabilidade no gerenciamento 
da qualidade de vida; registro e sistematização das açóes desenvolvidas, número de participantes, assuntos abordados, interatividade da população alvo, satisfação dos participantes frente à proposta; realização de oficinas de formação continuada para os bolsistas e docentes envolvidos que favoreçam a assimilação de conhecimentos, habilidades e atitudes para lidar com as situaçóes vivenciadas no dia a dia; capacitação dos acadêmicos para atuaçâo frente à comunidade, a partir do exercício da oralidade, comunicaçáo, postura, tomada de decisão, liderança e iniciativa; produçáo de material educativo relacionado com a saúde da criança e do adolescente; realizaçáo de reunióes semanais com o grupo de docentes e bolsistas, visando constante planejamento e reavaliação das açóes; produção de relatórios; incentivo à produção científica, a partir da elaboração de artigos científicos para publicação em periódicos e apresentação de trabalhos em eventos realizados pelo grupo.

Quanto à parte da pesquisa, esta envolveu a coleta de dados, por meio do Autoquestionnaire Qualité de Vie Enfant Imagé (AUQEI), utilizando a versão validada para o português por Assumpção et al. (2000). As coletas aconteciam antes dos encontros com os cuidadores dos pacientes internados no hospital pediátrico, sendo aplicado pelos acadêmicos, os quais foram previamente habilitados. A pesquisa foi aprovada pelo CEP da Univali, sob o número de parecer 1.499.851.

\section{Resultados e discussáo}

No período de março a dezembro de 2016, no Ambulatório de Endocrinologia, foram realizados 11 encontros com os cuidadores e pacientes, sendo quatro no primeiro semestre e sete no segundo, totalizando a participação de 111 cuidadores e pacientes. Já no Hospital Universitário Pequeno Anjo foram realizados 62 encontros, sendo 23 no primeiro semestre e 39 no segundo semestre, resultando na participação de 183 cuidadores.

O Círculo de Cultura iniciava sempre com os discentes realizando visitas nos quartos dos pacientes internados e fazendo um convite para os cuidadores participarem das conversas. As conversas aconteciam numa sala e a tematizaçáo iniciava com a seguinte pergunta: "O que vocês gostariam de conversar hoje?". E a partir desta pergunta, emergiram os temas das oficinas. Os principais temas elencados pelos cuidadores foram: internaçáo, importância do brincar, desenvolvimento da criança, alimentação, maternidade, família, Sistema Único de Saúde, redes de apoio à saúde, atividade física. Os temas geradores foram problematizados para subsidiar a discussão e, na busca de seu significado social, provocando uma postura ativa do grupo na consciência do mundo vivido. A proposta sempre foi dialógica e horizontal.

Estes temas geraram novos conhecimentos aos discentes e estes novos conhecimentos fazem parte do processo de aprendizagem, portanto, do ensino dos alunos. Um ensino que foge da pedagogia liberal (tradicional) e preconiza a pedagogia progressista (libertadora). Na pedagogia liberal tradicional, "os conhecimentos e valores sociais são acumulados pelas gerações adultas e repassados ao aluno como verdade", os métodos de ensino são baseados na exposição verbal e na demonstração da matéria, o professor tem uma postura autoritária e não mantém uma comunicação com o aluno. 
A pedagogia progressista designa "as tendências que, partindo de uma análise crítica das realidades sociais, sustentam implicitamente as finalidades sociopolíticas da educaçáo" (LIBÂNEO, 1999, p.32).

A educação em saúde passa a ser o elo integrador entre o saber técnico e o saber popular, marcado por uma colaboração mútua que atinge e reorienta a diversidade de práticas realizadas nos serviços de saúde. Mais do que um componente da atenção primária à saúde, exerce função de encorajamento e apoio para que pessoas e grupos sociais assumam maior controle sobre sua saúde e suas vidas (VASCONCELOS, 2001).

A proposta do projeto aspira também pelo nascimento de uma nova imagem profissional, responsável pela efetiva promoçáo da saúde, ao considerar o paciente em sua integridade física, psíquica e social, e não somente de um ponto de vista biológico (CAPRARA; FRANCO, 1999).

Considerando que a extensão universitária é sócio-historicamente consolidada nas Instituiçóes de Ensino Superior (IES), e a que a extensão anda de mãos dadas com o ensino e pesquisa, a metodologia deste projeto de extensão ocorre também no âmbito do ensino e da pesquisa.

As atividades desenvolvidas com o ensino aconteceram em três momentos: 1 . com o Círculo de Cultura com os cuidadores (já mencionado anteriormente); 2. nas atividades de formação continuada entre docentes e discentes; e 3. com a disciplina de Fisiopatologia de órgãos e sistemas, do quarto período do curso de Fisioterapia.

As atividades de formação continuada com os participantes do projeto de extensão foram sobre os principais temas geradores a serem abordados nas oficinas com os cuidadores no hospital e no ambulatório de endocrinologia. As formaçóes aconteceram semanalmente na Universidade. O processo de formação continuada dos participantes do projeto foi através de açôes pautadas na proposta pedagógica de Educação Continuada, na perspectiva de Paulo Freire. Esta proposta implica no encontro dos sujeitos para refletirem sobre sua realidade concreta, denunciando situações conflitantes e anunciando açóes que venham intervir neste contexto.

Freire (1987) denomina este encontro de saberes como Círculo de Cultura, que envolve a "problematização" e a "dialogicidade". A primeira permite ao sujeito se distanciar de sua experiência imediata e, em diálogo crítico com o outro, transcender a consciência ingênua, construindo sentidos para sua ação. A segunda pressupóe relaçóes de reciprocidade, nas quais os sujeitos educativos trocam experiências, saberes, necessidades do cotidiano profissional e existencial. Optou-se por esta proposta dialógica de formação porque foi a realizada junto aos cuidadores do ambulatório e do hospital. Ao total, ocorreram 62 reunióes entre os acadêmicos e as docentes do projeto. As reunióes foram realizadas pelos discentes e docentes, os quais elaboraram estratégias interativas que foram utilizadas durante o acolhimento e no encontro com os cuidadores, tais como jogos, dinâmicas, material visual, dentre outros, e temas que também surgiram durante os encontros ou que tenham vínculo com o intuito do projeto.

Os aspectos que favoreceram a formaçáo continuada foram a mobilizaçáo dos saberes docentes: o saber da experiência, o saber do conhecimento e o saber pedagógico. O saber da experiência é o saber que constrói a base de elementos que irão nortear a prática, bem como o que é produzido na prática num processo de reflexão e troca com 
os colegas, ou seja, sáo aqueles saberes adquiridos durante toda a jornada escolar com os alunos, por diferentes professores. O saber do conhecimento envolve a revisão da função da escola na transmissão dos conhecimentos e as suas especialidades num contexto contemporâneo. Por último, o saber pedagógico, que compreende o conhecimento aliado ao saber da experiência e dos conteúdos específicos, e que será construído a partir das necessidades pedagógicas reais (PIMENTA, 2009).

O terceiro momento foi na disciplina de Fisiopatologia, que tem cinco unidades de ensino (fisiopatologia pulmonar, fisiopatologia cardíaca, fisiopatologia sistema nervoso, fisiopatologia osteomioarticular e fisiopatologia uroginecológica) e, em todas as unidades de ensino, se teve como objetivo "Compreender o processo de extensão universitária no projeto de extensão Educação em Saúde com cuidadores, crianças e adolescentes no Hospital Universitário Pequeno Anjo (HUPA)".

A estratégia de ensino utilizada para alcançar este objetivo foi a de vivenciar as atividades desenvolvidas pelos participantes do projeto de extensão. Nestas atividades, os acadêmicos da disciplina de Fisiopatologia acompanharam e observaram pelo menos cinco encontros do projeto de extensáo no Hospital, que ocorreram no período da tarde de segunda-feira a quarta-feira. Para que os alunos não faltassem às aulas teóricas da disciplina de Fisiopatologia, as atividades de observaçóes aconteceram somente nas terças e quartas-feiras. As participaçóes foram descritas num diário de campo e, no final do semestre, os alunos apresentaram-nos numa roda de conversa em sala de aula. Todos os alunos deveriam seguir as normas de biossegurança do hospital. Neste momento de articulação entre ensino e extensão, os alunos tiveram a possibilidade de sair da sala de aula e experienciar uma atividade extramuros da Universidade e com inserção social.

As atividades de ensino que aconteceram no projeto de extensão preconizam a transformação dos modelos de ensino tradicional para um ensino progressista libertador. O estudo de Backes, Moya e Prado (2011) afirma que as transformaçóes dos processos de ensino na ordem paradigmática e estrutural propóem novos métodos de ensino, centrados na aprendizagem do aluno, ou seja, uma nova concepçáo do trabalho docente para promover a aprendizagem significativa, habilidades de pensamento crítico e reflexivo, e, ainda, aprender a aprender, mediante a revisáo do exercício profissional. Também há nisso o que Woods (1995) afirma acerca da necessidade de alargar as opçóes metodológicas e epistemológicas, para que o ensino, cada vez menos conformista, seja mais criativo e dinâmico.

No que concerne às atividades de pesquisa, foi publicado um artigo científico, bem como foram apresentados trabalhos em eventos científicos e, ainda, está em andamento uma pesquisa científica. $\mathrm{O}$ artigo intitulado "Caracterização dos cuidadores das crianças e adolescentes atendidos pelo projeto de extensão de um hospital universitário infantil" foi publicado na Revista Brasileira de Tecnologias Sociais, no ano de 2016. Ainda neste ano, os alunos apresentaram e publicaram resumos em anais de eventos científicos e em revista do evento. Os eventos foram os seguintes: XX Encontro de Iniciação Científica, XVI Encontro de Pós-Graduação, X INIC Jr e VI INID da Universidade do Vale do Paraíba, o XVIII Encontro Catarinense de Enfermagem Pediátrica e Neonatal e I Jornada do GEPESCA, e, ainda, a publicação dos resumos na Revista UNIVAP Online. 
Ainda sobre as atividades de pesquisa, está sendo realizada uma pesquisa científica sobre a qualidade de vida das crianças internadas, denominada "Avaliaçáo da qualidade de vida de cuidadores e crianças internadas em ambiente hospitalar", aprovada pelo Comite de Ética e Pesquisa, sob parecer n. 1.499.851. Esta pesquisa tem o objetivo geral de avaliar a qualidade de vida de crianças e cuidadores atendidos em ambiente hospitalar e ambulatorial, o quanto as características nutricionais, clínicas e sociodemográficas influenciam na qualidade de vida das crianças. E, especificamente, de: identificar o perfil sociodemográfico, clínico e nutricional das crianças; caracterizar os resultados de domínios apresentados no teste de qualidade de vida das crianças e os cuidadores; analisar os impactos que estes domínios tem na qualidade de vida das crianças e cuidadores; associar os escores de qualidade de vida com as características nutricionais, sociodemográficas e clínicas das crianças. Todos os objetivos da pesquisa articulam os 3 cursos da área da saúde envolvidos no projeto de extensão: a fisioterapia, a nutrição e a psicologia.

Ainda, nas atividades relacionadas à pesquisa, aplicou-se a escala de AUQEI, a qual é adequada à especificidade e ao contexto em pediatria, incluindo a dimensáo subjetiva. Esta escala foi desenvolvida por Manificat e Dazord, em 1997, em estudo com 95 crianças, das quais $60 \%$ sem problemas de saúde, $26 \%$ pós-transplante renal e $14 \%$ soropositivas para HIV, com idades entre 3 anos e 9 meses a 12 anos e 6 meses. Sua versão atual visa avaliar a sensação de bem-estar ou satisfação das crianças em relação a alguns aspectos da vida, sem partir de inferências realizadas sobre o seu desempenho e produtividade.

Visualizada a partir de quatro figuras que são associadas a diversos domínios da vida, é composta de 26 questôes que exploram relaçôes familiares, sociais, atividades, saúde, funções corporais e separação, 18 delas contidas em 4 fatores: autonomia (questôes relativas à independência, relaçóes com companheiros e avaliaçôes); lazer (questóes relativas a férias, aniversário e relaçôes com avós); funções (questôes relativas à atividade na escola, a refeiçôes, deitar, ida a médico); e família (questóes relativas à opiniáo quanto às figuras parentais e delas quanto a si mesmo).

Foi validada por Assumpção et al. (2000), no Brasil, junto a 353 crianças saudáveis pertencentes a uma escola privada do município de São Paulo, atestando suas propriedades psicométricas e obtendo uma nota de corte de 48, abaixo da qual a qualidade de vida das crianças estudadas foi considerada prejudicada. De início, é solicitado que à criança apresente uma experiência própria vivida frente a cada uma das alternativas reportadas pelas quatro imagens. Uma vez identificados os estados emocionais correspondentes, passa-se à leitura das questóes, pedindo que a criança assinale, sem tempo definido.

Esta pesquisa é um Trabalho de Conclusão de Curso da Fisioterapia e que também foi aprovado no edital de pesquisa do CNPq -PIBIC. Já foram realizados 98 questionários com as crianças e, neste momento, o projeto está na fase de análise dos dados coletados. Desta forma, os resultados desta pesquisa serão apresentados no Seminário de Iniciaçáo Científica da Univali, em outubro de 2017, e depois enviados para avaliação em alguma revista científica.

A pesquisa em andamento pelo projeto de extensão é de muita importância, pois a partir dos seus resultados, será conhecida a real qualidade de vida das crianças em 
foco. A pesquisa pode ser considerada - utilizando-se a imagem de Valêncio (2000) como a voz desse outro, constituído pela realidade social. Ao náo se levar em conta essa voz, não seria possível conhecer a qualidade de vida das crianças internadas. E mais: no ano de 2016, o projeto publicou um artigo na Revista Brasileira de Tecnologias Sociais (BARRETA et al., 2016), dois artigos completos em anais de evento internacional, sendo eles: "Humanização e educação em saúde junto aos cuidadores, crianças e adolescentes de um ambulatório de saúde familiar e comunitária (CHESANI et al., 2016)" e "Projeto de extensão: humanizaçáo e educação em saúde junto aos cuidadores, crianças e adolescentes no hospital universitário infantil (ENGEL et al., 2016)". Ainda, um resumo em anais: "Educaçẫo em saúde com os cuidadores, crianças e adolescentes de um ambulatório de saúde familiar e comunitária" (CHESANI et al., 2016). Somado a isso, acredita-se que a pesquisa poderá gerar publicaçóes que socializaram alguns dos conhecimentos produzidos na experiência.

\section{Consideraçóes finais}

A indissociabilidade pesquisa extensão ensino convoca os docentes e os discentes universitários à articulaçáo de saberes: o saber da experiência, o saber do conhecimento e o saber pedagógico.

O ensino consistiu de ocasióes para a reflexão e a (re)construção de conceitos e valores em que estavam mergulhados no seu modelo tradicional, pois possibilitou o uso de técnicas pedagógicas para a aprendizagem capazes de tornar a aprendizagem dos conteúdos mais prazerosa, numa perspectiva mais dialogal, reflexiva e criativa, a fim de ressignificar as práticas dos discentes. Nas reunióes, evitavam-se os métodos tradicionais de transmissão de conteúdo, procurando-se discutir por meio de didáticas mais dinâmicas.

A extensão e o ensino não são acessórios à pesquisa, mas naturais dela, haja vista que se a produção científica do conhecimento quiser ser efetiva e intervir para modificar a realidade estudada - voltando a enriquecer-se, nesse processo, por dela alimentar-se continuamente - não há relevância social da pesquisa sem a indissociabilidade.

\section{Referências}

ASSUMPÇÃO, J. R. et al. Escala de avaliação de qualidade de vida: (AUQEI Autoquestionnaire Qualité de Vie Enfant Imagé) validade e confiabilidade de uma escala para qualidade de vida em crianças de 4 a 12 anos. Arq. Neuro-Psiquiatr., São Paulo, v. 58 , n. 1, p. 119-127, mar. 2000.

BACKES, V.M.S.; MOYÁ, J.L.M.; PRADO, M.L. Processo de construção do conhecimento pedagógico do docente universitário de enfermagem. Rev. Latino-Am. Enfermagem. v. 19, n.2, mar./abr. 2011. 
BARRETTA, C.; OLIVEIRA, M. A. M.; DIAS, A.M.; CHESANI, F. H. Caracterização dos cuidadores das crianças e adolescentes atendidos pelo projeto de extensão de um hospital universitário infantil. Revista Brasileira de Tecnologia Social, v. 3, p. 15-24, 2016.

BRASIL. Constituição (1988). Constituição da República Federativa do Brasil. Brasília, DF: Senado Federal: Centro Gráfico, 1988. 292 p.

CAPRARA, A.; FRANCO, A.L.S. A Relação paciente-médico: para uma humanização da prática médica. Cad. Saúde Pública, Rio de Janeiro, v. 15, n. 3, p. 647-654, Sept. 1999.

CHESANI, F. H. et al. Humanização e educação em saúde junto aos cuidadores, crianças e adolescentes de um ambulatório de saúde familiar e comunitária. Educação e Ciência para a cidadania global, São José dos Campos, UNIVAP, v.1, p.1-4, 2016.

CHESANI, F.H. et al. Educação em saúde com os cuidadores, crianças e adolescentes de um ambulatório de Saúde Familiar e Comunitária In: ENCONTRO LATINO AMERICANO DE INICIAÇÃO CIENTÍFICA, XX., ENCONTRO LATINO AMERICANO DE PÓS-GRADUAÇÃO, XVI., e ENCONTRO DE INICIAÇÃO À DOCÊNCIA, XI., 2016, São José dos Campos. São José dos Campos: Univap, 2016. v.22. p.157-157.

ENGEL, B.C. et al. Projeto de extensão: humanização e educação em saúde junto aos cuidadores, crianças e adolescentes no hospital universitário infantil. Educação e Ciência para a cidadania global, São José dos Campos, UNIVAP, v.1, p.1-6, 2016.

FREIRE, P.R.N. Pedagogia do oprimido. Rio de Janeiro: Paz e Terra, 1987.

GADOTTI, M. Convite a leitura de Paulo Freire. São Paulo: Scipione, 1991.

GARRAFA, V. (Org.). Extensão: a universidade construindo saber e cidadania: relatório de atividades, 1987/1988. Brasília: Ed. UNB, 1989.

LIBÂNEO, J.C. Democratização da escola pública: a pedagogia crítico-social dos conteúdos. 16. ed. São Paulo: Cortez, 1999.

MANIFICAT, S., DAZORD, A. Évaluation de la qualité de vie de l'enfant: validation d'un questionnaire, premiers résultats. Neuropsychiatr Enfance Adolesc., v.45, p.106-114, 1997.

MOITA, F.M.G.S.C.; ANDRADE, F.C.B. Ensino-pesquisa-extensão: um exercício de indissociabilidade na pós-graduação. Rev. Bras. Educ., Rio de Janeiro, v. 14, n. 41, p. 269280, 2009.

PIMENTA, S.G. Saberes pedagógicos e atividades docente. 7.ed. São Paulo: Cortez, 2009.

VALÊNCIO, N.F.L.S. A indissociabilidade entre ensino/pesquisa/extensão: verdades e mentiras sobre o pensar e o fazer da Universidade Pública no Brasil. Proposta, n. 83, p. 72-81, dez. 1999/fev. 2000. 
VASCONCELOS, E.M. Redefinindo as práticas de saúde a partir da educação popular nos serviços de saúde.

In: . (Org.). A saúde nas palavras e nos gestos: reflexões da rede de educação popular e saúde. São Paulo: Hucitec, 2001. p.11-9.

WOODS, P. Aspectos sociais da criatividade do professor. In: NÓVOA, António (Org.). Profissão professor. Porto: Porto Editora, 1995. 